\title{
SIMULAÇÃO DO SEQUESTRO GEOLÓGICO DO DIÓXIDO DE CARBONO $\left(\mathrm{CO}_{2}\right)$
}

\author{
P. J. ZUCATELli ${ }^{1}$, A. P. MENEGUELO ${ }^{2}$, C. A. M. SILVA ${ }^{3}$, J. L. GIURIATTO ${ }^{4}$ \\ ${ }^{1}$ Universidade Federal do Espírito Santo, Aluno do Programa de Pós-Graduação Stricto \\ Sensu - Mestrado em Energia. \\ ${ }^{2}$ Universidade Federal do Espírito Santo, Professora do Departamento de Engenharias e \\ Tecnologias e do Programa de Pós-Graduação Stricto Sensu - Mestrado em Energia. \\ ${ }^{3}$ Universidade Federal do Espírito Santo, Professor do Departamento de Ciências Naturais. \\ ${ }^{4}$ Engenheiro de Petróleo da Empresa Schlumberger. \\ E-mail para contato: pedrojrzucatelli@gmail.com
}

\begin{abstract}
RESUMO - Um dos desafios da humanidade para o século XXI é a busca de soluções seguras para enfrentarmos o aquecimento global e as consequentes mudanças climáticas causadas pelo aumento substancial das emissões de gases de efeito estufa, em especial o dióxido de carbono $\left(\mathrm{CO}_{2}\right)$. O sequestro de carbono através da captura, transporte e armazenamento geológico de $\mathrm{CO}_{2}$ é uma importante alternativa na redução das emissões e estabilização da concentração atmosférica dos gases de efeito estufa em uma perspectiva de desenvolvimento sustentável, e está baseado no princípio de "devolver o carbono ao subsolo". A dificuldade está, por exemplo, em saber como o reservatório e os fluidos presentes irão se comportar com o armazenamento, qual será o destino do $\mathrm{CO}_{2}$ após a sua injeção e qual será o risco geológico de vazamento. Um planejamento estratégico e cuidadoso, baseado em modelagem, simulação e análise do modelo envolvido, é necessário após a aplicação da injeção de $\mathrm{CO}_{2}$ nesses reservatórios. Isso porque a modelagem numérica é, provavelmente, a única ferramenta disponível para avaliar e prever o destino de $\mathrm{CO}_{2}$ injetado em reservatórios geológicos profundos, e particularmente, em aquíferos salinos. Neste trabalho foi utilizado o modelo CO2STORE, implementado no software ECLIPSE 2010.2, plataforma ECLIPSE 300, visando analisar o comportamento do $\mathrm{CO}_{2}$ durante o período de 227,5 anos (83 063 dias), sendo 6 anos e 5 meses de injeção com, aproximadamente, $5,07 \times 10^{8} \mathrm{~m}^{3}$ de $\mathrm{CO}_{2}$ armazenado em um aquífero salino.
\end{abstract}

\section{INTRODUÇÃO}

Desde a Revolução Industrial (século XVIII), os combustíveis fósseis são utilizados como fonte de energia, contribuindo para o aumento da concentração de $\mathrm{CO}_{2}$ (dióxido de carbono) na atmosfera. Devido a este crescente aumento das emissões, teve início, no século XX, o conceito sistêmico que articula desenvolvimento global incorporando o desenvolvimento ambiental: Desenvolvimento Sustentável. 
De acordo com COSTA (2009), ações antrópicas como a queima de combustíveis fósseis (carvão, petróleo e gás natural), utilização de aerossóis, combustão de biomassa, além de outras atividades básicas e intensas como o cultivo de arroz e criação de gado, liberam para atmosfera um conjunto de gases chamados "Gases do Efeito Estufa" (GEE). Os principais gases responsáveis pelo efeito estufa são: óxido nitroso $\left(\mathrm{N}_{2} \mathrm{O}\right)$, metano $\left(\mathrm{CH}_{4}\right)$ e o dióxido de carbono $\left(\mathrm{CO}_{2}\right)$ por serem os mais abundantes.

$\mathrm{O} \mathrm{CO}_{2}$, em especial, tem efeitos danosos para o meio ambiente, principalmente devido à velocidade crescente com que vem sendo produzido para atender às necessidades do modelo consumista da vida atual. A emissão de GEE, principalmente o $\mathrm{CO}_{2}$, provoca o aquecimento global e, consequentemente, as mudanças climáticas (IPCC, 2005 apud COSTA, 2009).

Tendo como base o conceito de sustentabilidade e a visão de que os combustíveis fósseis são um dos grandes responsáveis pelo aumento das emissões de $\mathrm{CO}_{2}$, a indústria de exploração e produção de petróleo possui as ferramentas necessárias para auxiliar na contenção do crescimento das emissões através da tecnologia emergente conhecida como "Sequestro ou Armazenamento Geológico de $\mathrm{CO}_{2}$ ", conforme observa-se na Figura 1. A dificuldade está, por exemplo, em saber como o reservatório e os fluidos presentes irão se comportar com o armazenamento, qual será o destino do $\mathrm{CO}_{2}$ após a sua injeção e qual será o risco geológico de vazamento.

Um planejamento estratégico e cuidadoso, baseado em modelagem, simulação e análise do modelo envolvido, é necessário após a aplicação da injeção de $\mathrm{CO}_{2}$ nesses reservatórios. Isso porque a modelagem numérica é, provavelmente, a única ferramenta disponível para avaliar e prever o destino de $\mathrm{CO}_{2}$ injetado em reservatórios geológicos profundos e, particularmente, em aquíferos salinos (lençóis de água subterrânea com água salobra não aproveitável).

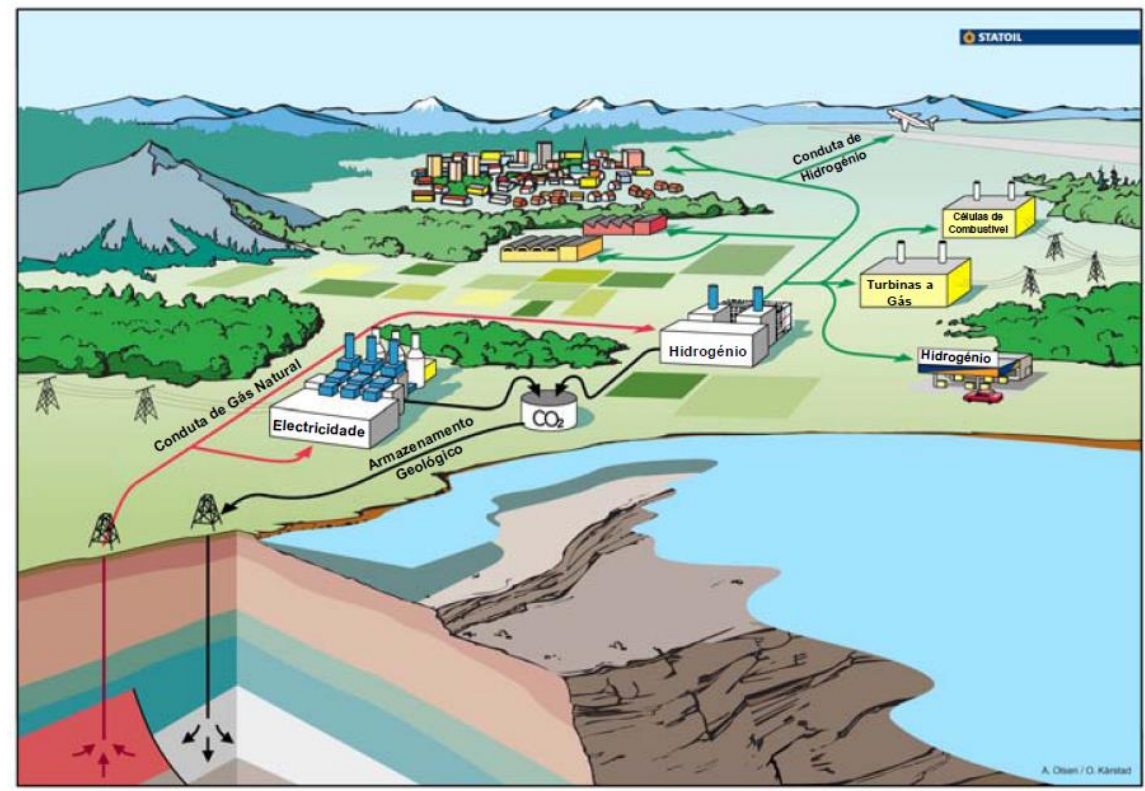

Figura 1 - Situação futura possível: combustíveis fósseis gerando eletricidade e hidrogênio, e ao mesmo tempo captura, transporte e armazenamento geológico de $\mathrm{CO}_{2}$.

Fonte: STATOIL, 2011. 


\section{METODOLOGIA}

Neste trabalho foi utilizado o modelo CO2STORE, implementado no software ECLIPSE 2010.2, plataforma ECLIPSE 300, visando analisar o comportamento do $\mathrm{CO}_{2}$ durante o período de 227,5 anos (83 063 dias), sendo 6 anos e 5 meses de injeção com, aproximadamente, $5,07 \times 10^{8} \mathrm{~m}^{3}$ de $\mathrm{CO}_{2}$ armazenado em um aquífero salino. O simulador ECLIPSE 2010.2 é uma poderosa ferramenta computacional para a análise de reservatórios de petróleo. Permite a modelagem dos fluidos do reservatório sob diferentes condições, o que torna os resultados mais reais. Através deste software, é possível também a simulação de sistemas com mais de quatro componentes, onde este quarto componente pode vir da injeção de fluidos que sejam miscíveis aos hidrocarbonetos do reservatório.

\section{SIMULAÇÃO NUMÉRICA DE RESERVATÓRIOS}

Os fluidos envolvidos neste estudo são gás $\left(\mathrm{CO}_{2}\right)$ que é injetado, e os sais e água do reservatório propriamente. $\mathrm{O}$ modelo do problema contempla um poço injetor. O poço injetor está aberto para injetar com uma vazão de gás variável. A dimensão do reservatório é de 7000 $\mathrm{m}$ de comprimento e de largura e 1,827 m de altura (Figura 2); o mesmo está a uma profundidade de $1411,4 \mathrm{~m}$.

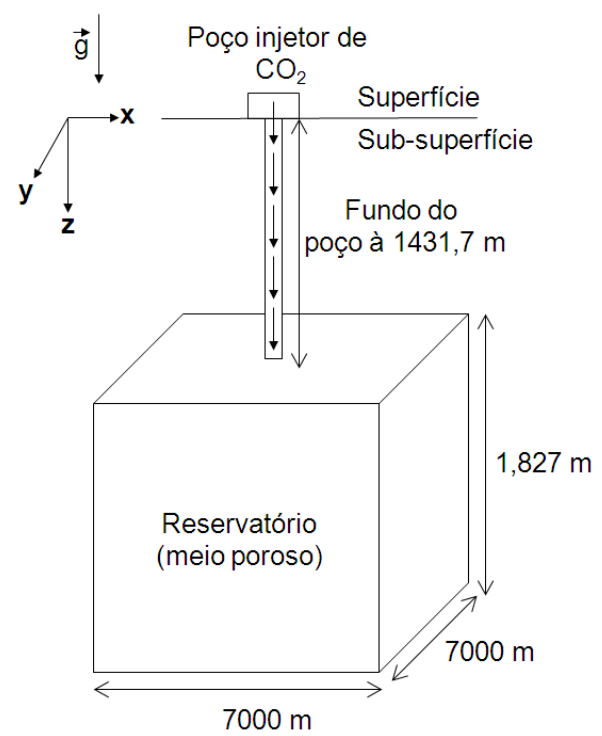

Figura 2 - Ilustração do modelo físico.

A temperatura do reservatório é de $32,2{ }^{\circ} \mathrm{C}$ e os componentes presentes são $\mathrm{H}_{2} \mathrm{O}, \mathrm{CO}_{2}$, $\mathrm{NaCl}, \mathrm{CaCl}_{2}$, com respectivas frações molares, 0,$9109 ; 0,0 ; 0,0741 ; 0,015$. O componente $\mathrm{NaCl}$ (densidade de $2170,0 \mathrm{~kg} / \mathrm{m}^{3}$ ) pode estar presente no reservatório de forma sólida cuja saturação pode variar entre 0,0 a 0,8 . Entretanto, vale lembrar que componentes sólidos podem ser convertidos em componentes fluidos através de reações químicas, podem ser adsorvidos pela formação rochosa (reduzindo o volume poroso), e, além disso, sólidos suspensos podem ser transportados pelo fluxo de fluidos. 
A pressão de referência da rocha é de 137,2 bar e a compressibilidade da rocha é de $7,25 \times 10^{-5}$ 1/bar. O reservatório é tridimensional, dividido em 70 blocos na direção $\mathrm{x}, 70$ blocos na direção y e 10 blocos na direção z. O poço injetor de gás $\left(\mathrm{CO}_{2}\right)$ está implementado na célula $i=35$ e $j=35$, com uma profundidade de referência para a pressão de fundo do poço de 1431,7 m. A pressão de fundo do poço é de 400 bar.

\section{RESULTADOS E DISCUSSÕES}

$\mathrm{Na}$ simulação deste projeto, a injeção de $\mathrm{CO}_{2}$ no reservatório se inicia em 01 de agosto de 2004 e se encerra em 01 de janeiro de 2011, totalizando, dessa forma, 6 anos e 5 meses de injeção com, aproximadamente, $5,07 \times 10^{8} \mathrm{~m}^{3}$ de $\mathrm{CO}_{2}$ armazenado. O monitoramento do comportamento do $\mathrm{CO}_{2}$ no reservatório se inicia no dia 01 de agosto de 2004 e se encerra no dia 31 de dezembro de 2231, totalizando 227,5 anos (83 063 dias).

Na Figura 3 observamos a variação da pressão no reservatório durante os 83063 dias. Percebemos um aumento significativo da pressão durante os primeiros 7 anos (2555 dias), passando dos 174,274 bar para 327 bar, permanecendo constante após isso. Vale ressaltar que este período de variação da pressão corresponde, aproximadamente, ao período de injeção.

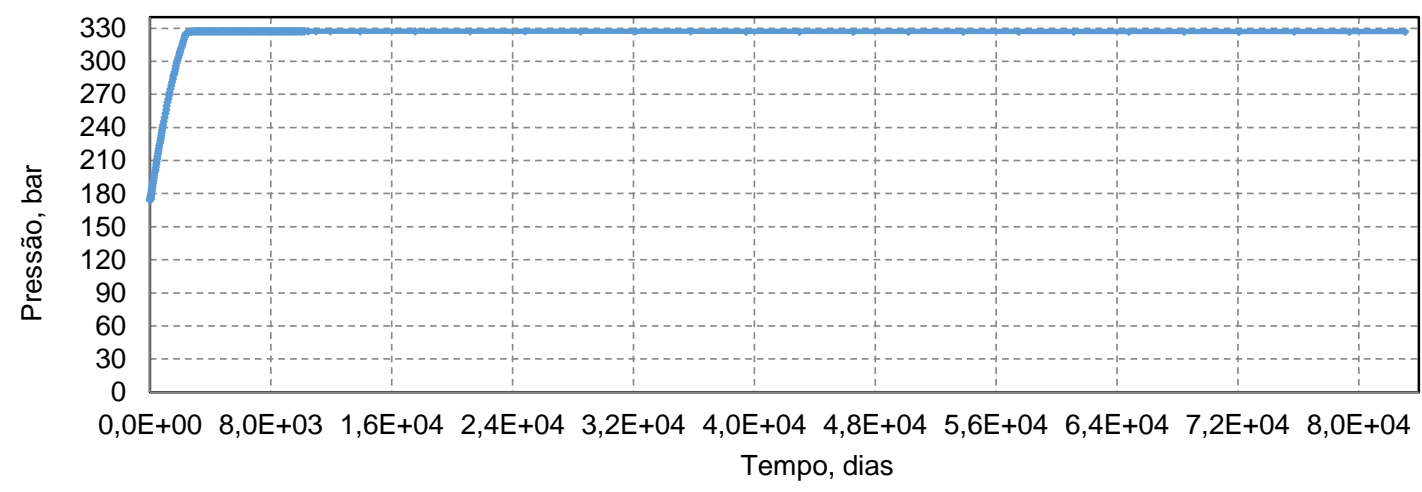

Figura 3 - Variação da pressão no reservatório.

Observamos, na Figura 4, a variação do volume de gás no reservatório (fase líquida). Durante os primeiros 2,6 anos (949 dias), o volume de gás no reservatório (fase líquida) foi igual a $0,0 \mathrm{~m}^{3}$. Durante os 3,5 anos seguintes, o volume de gás na fase líquida, no reservatório, saltou de $0,0 \mathrm{~m}^{3}$ para $2882873 \mathrm{~m}^{3}$. A curva se mantem crescente até o final do período analisado, indicando que uma maior quantidade de $\mathrm{CO}_{2}$ passaria para a fase líquida. $\mathrm{O}$ volume de gás na fase líquida, no reservatório, registrado no final dos 227,5 anos (83 063 dias) foi de 4 $731262 \mathrm{~m}^{3}$. 


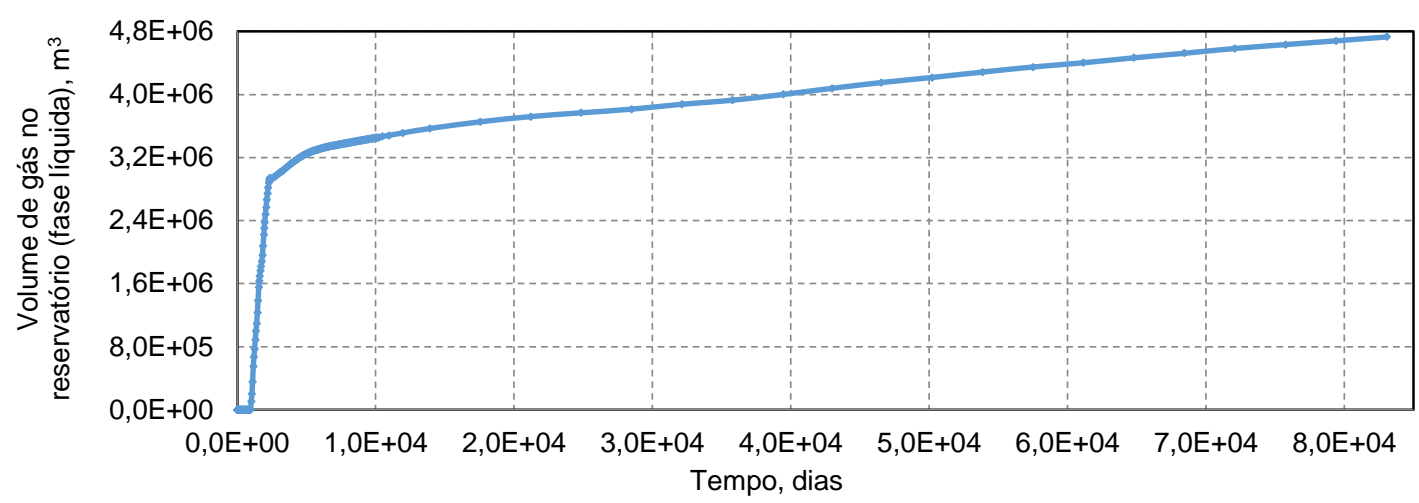

Figura 4 - Variação do volume de gás no reservatório (fase líquida).

Já na Figura 5, onde é apresentada a curva da variação do volume de gás no reservatório (fase gasosa), podemos observar que durante os primeiros 6,2 anos (2278 dias) o volume citado salta dos $0,0 \mathrm{~m}^{3}$ para $144071920 \mathrm{~m}^{3}$. Após esse período, esse volume teve pequenas variações, permanecendo a curva quase constante. Este período de variação do volume de gás no reservatório (fase gasosa) é, aproximadamente, igual ao período de injeção. O volume de gás na fase gasosa, no reservatório, registrado no final dos 227,5 anos (83 063 dias) foi de 144938 $464 \mathrm{~m}^{3}$.

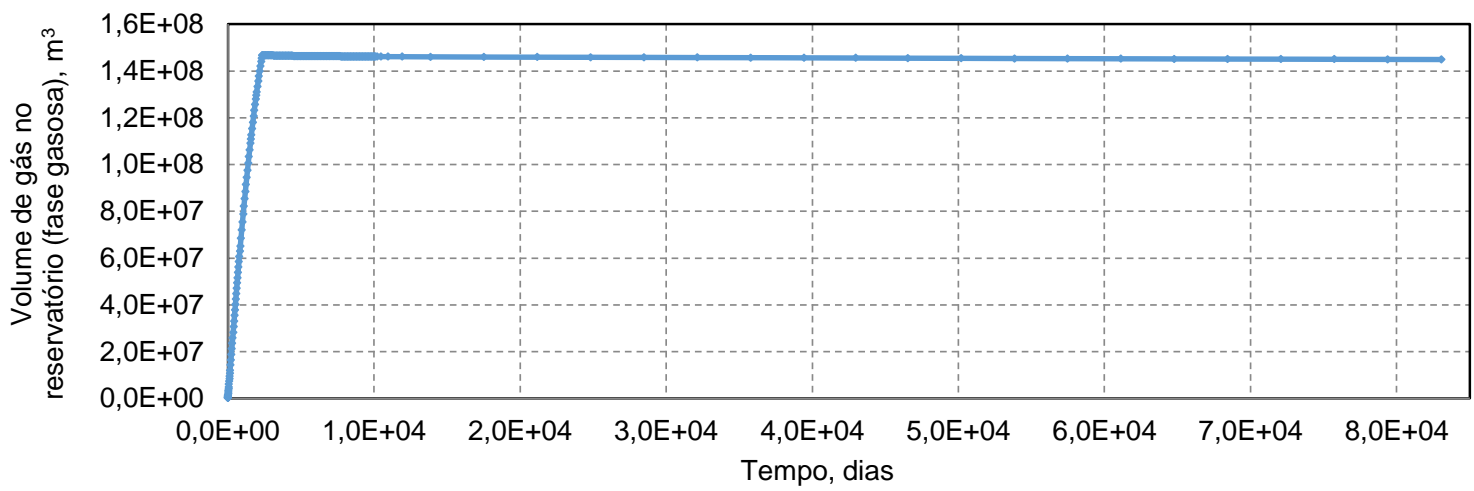

Figura 5 - Variação do volume de gás no reservatório (fase gasosa).

As Figuras 6 a 12, em duas dimensões, foram obtidas através do software ECLIPSE 2010.2. A visualização está em planta e a malha é 70x70, com 7000 metros em x e em y. Nas Figuras 6 a 8 observamos a variação da pressão no reservatório.

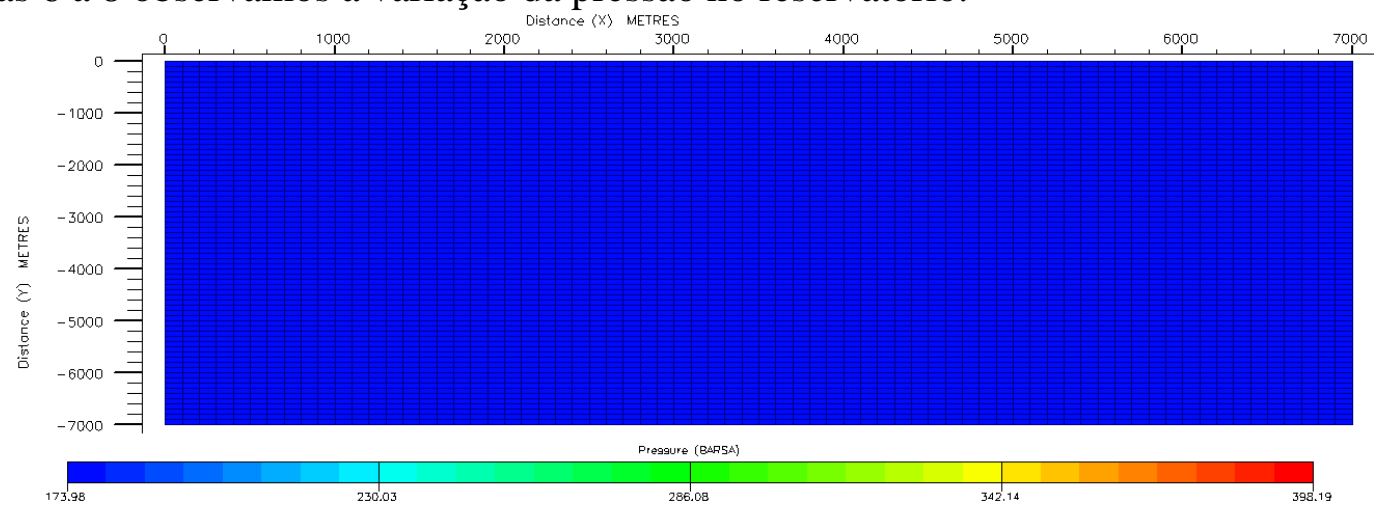

Figura 6 - Pressão no reservatório em 01 de agosto de 2004. 


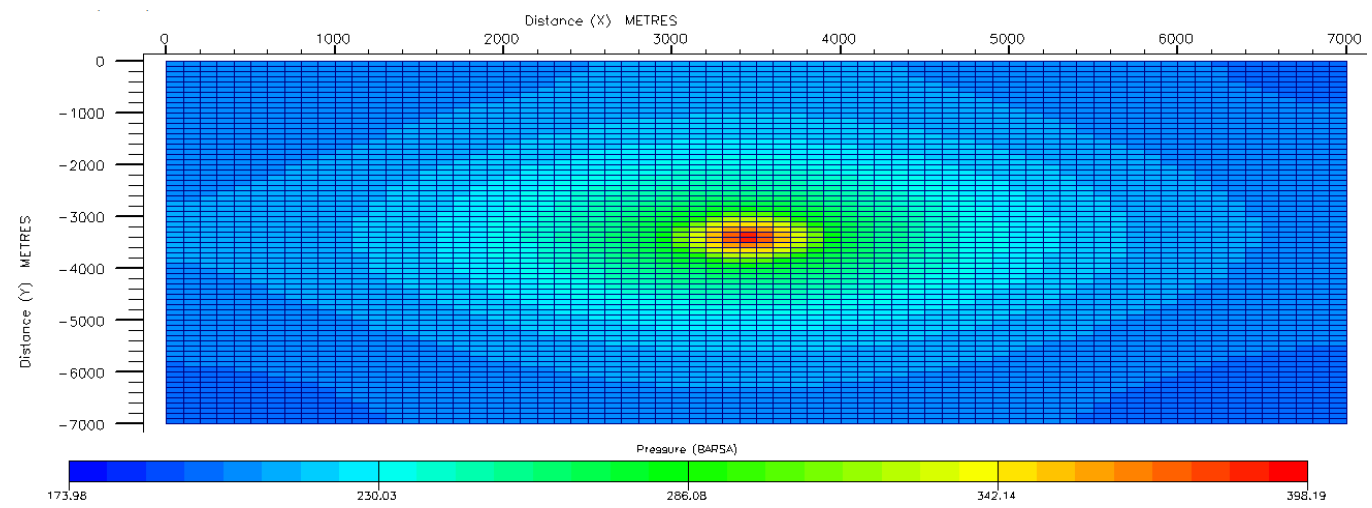

Figura 7 - Pressão no reservatório em 01 de fevereiro de 2006.

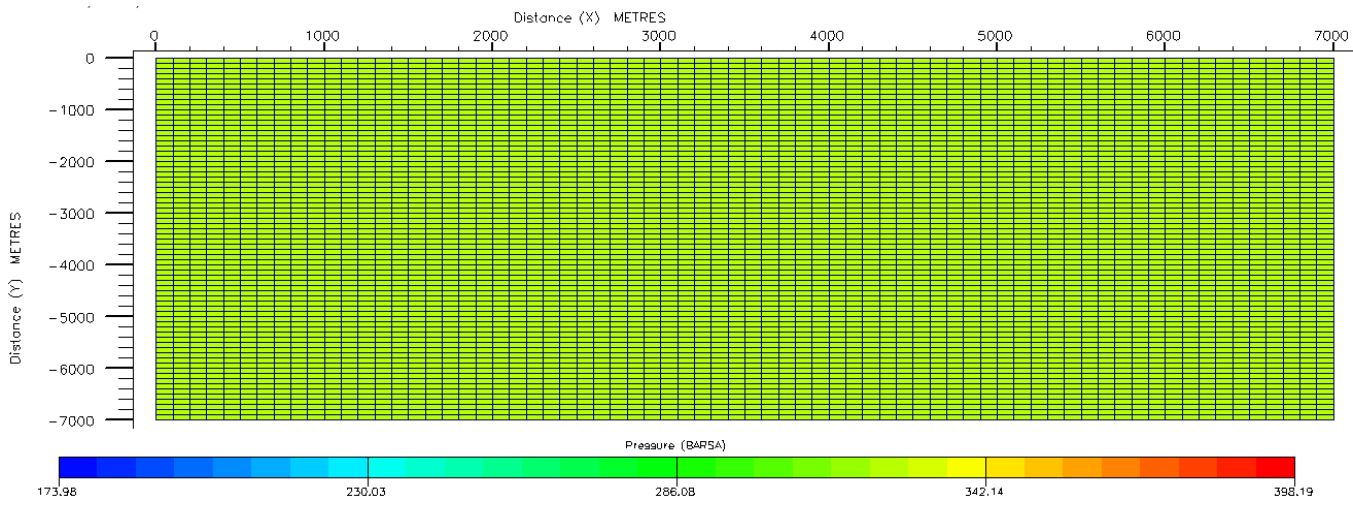

Figura 8 - Pressão no reservatório em 31 de dezembro de 2231.

A variação do $\mathrm{pH}$ no reservatório, durante os 227,5 anos (83 063 dias), pode ser observada através das Figuras 9 e 10. Segundo SCHÜTZ (2010), a adição de $\mathrm{CO}_{2}$ em água conduz, inicialmente, a um aumento na quantidade de $\mathrm{CO}_{2}$ dissolvido. $\mathrm{O}_{2} \mathrm{CO}_{2}$ dissolvido, por sua vez, reage com a água formando ácido carbônico $\left(\mathrm{H}_{2} \mathrm{CO}_{3}\right)$. Quando forma-se o ácido carbônico, o mesmo se dissocia para formar íons bicarbonatos $\left(\mathrm{HCO}_{3}{ }^{-}\right)$. Estes íons serão, posteriormente, dissociados para formar íons carbonatos $\left(\mathrm{CO}_{3}^{-2}\right)$. Ao final das reações teremos o aumento de íons de hidrogênio $\left(\mathrm{H}^{+}\right)$em solução, reduzindo o $\mathrm{pH}$ da água de formação do reservatório. (IPCC, 2005; DRUCKENMILLER E MAROTO-VALER, 2005 apud SCHÜTZ, 2010).

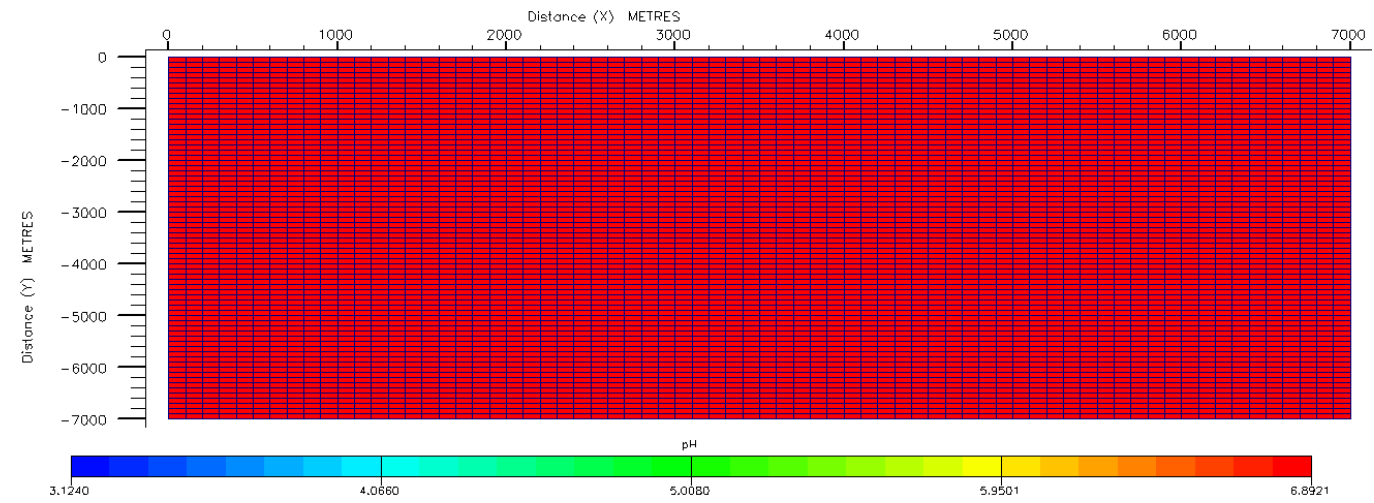

Figura $9-$ pH no reservatório em 01 de agosto de 2004. 


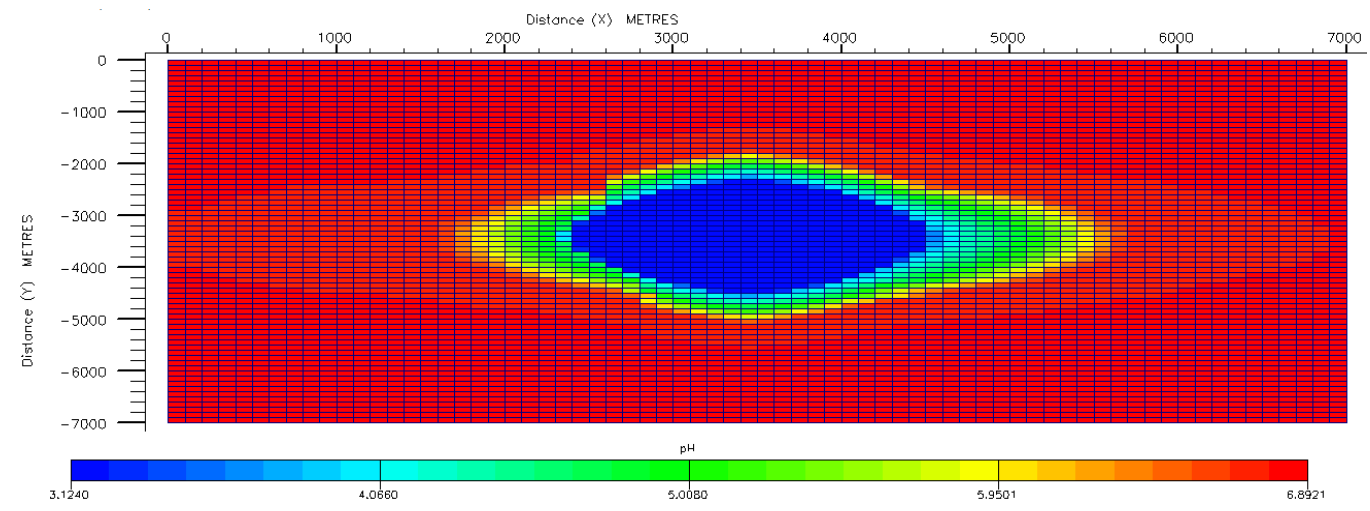

Figura 10 - pH no reservatório em 31 de dezembro de 2231.

Já a saturação de gás no reservatório pode ser observada nas Figuras 11 e 12.

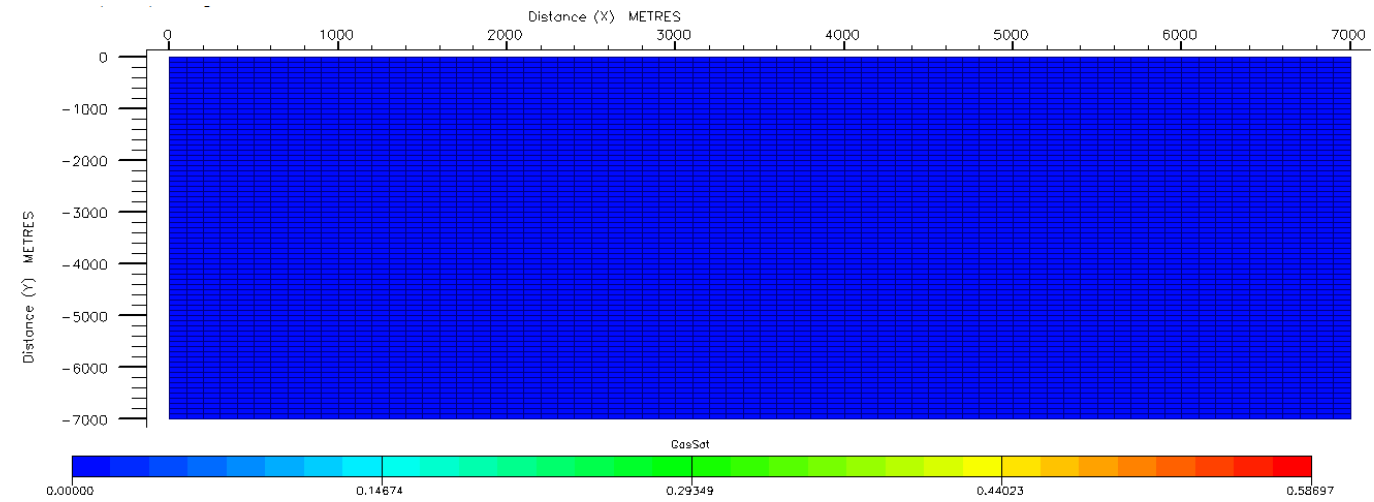

Figura 11 - Saturação de gás no reservatório em 01 de agosto de 2004.

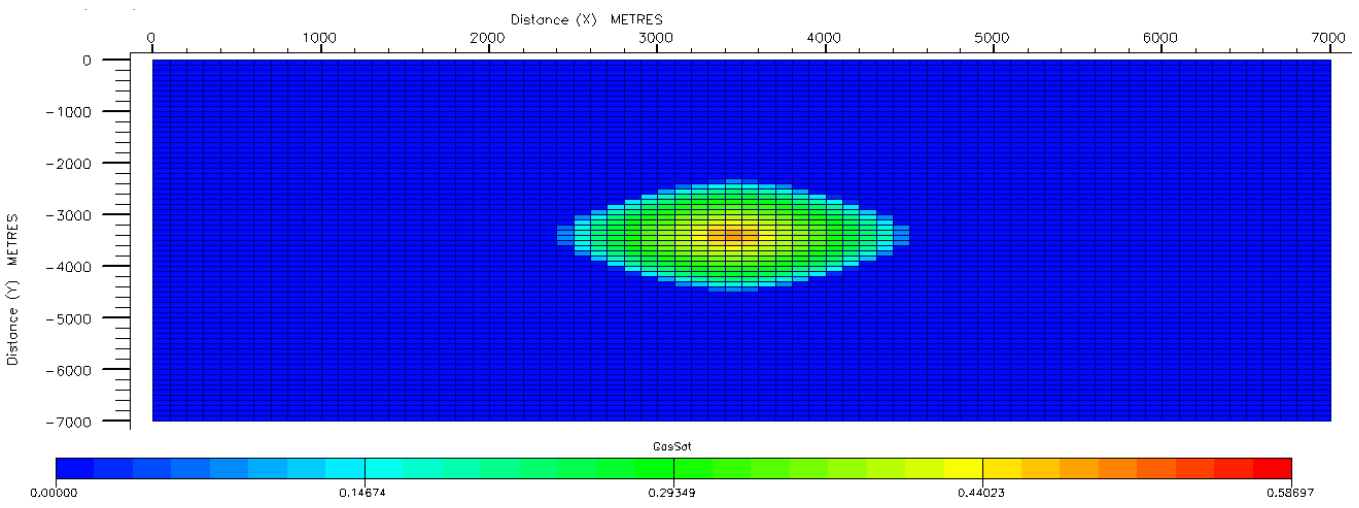

Figura 12 - Saturação de gás no reservatório em 31 de dezembro de 2231.

O resultado demonstra que o reservatório tem uma capacidade muito maior de armazenamento, ou seja, seria possível continuar injetando $\mathrm{CO}_{2}$ nesse reservatório. Uma observação importante, neste caso, é sobre a necessidade da validação de que não há perigo de escape de $\mathrm{CO}_{2}$ por poços abandonados, falhas e/ou fraturas, pois isto não foi realizado neste estudo. A área saturada de gás no reservatório é de, aproximadamente, $4,41 \times 10^{6} \mathrm{~m}^{2}$. 


\section{CONSIDERAÇÕES FINAIS}

A avaliação do risco de injeção de $\mathrm{CO}_{2}$ em reservatórios geológicos profundos, como reservatórios de campos maduros de hidrocarbonetos e aquíferos salinos, implica em uma plena compreensão das interações físicas e químicas entre $\mathrm{CO}_{2}$, água de formação, reservatório e rochas capeadoras. Além disso, essa avaliação contribui para o estudo dos cenários de escapamento de $\mathrm{CO}_{2}$ que incluem: fuga através das rochas capeadoras, falhas, fraturas e poços abandonados, difusão em água, dissolução de $\mathrm{CO}_{2}$ na água e subsequente transporte de $\mathrm{CO}_{2}$ pela água dos aquíferos.

Devido a uma série de fatores, como a complexidade envolvida na modelagem de reservatórios de campos maduros de hidrocarbonetos, disponibilidade pública de dados geológicos, tempo para execução deste projeto e por ser um assunto relativamente novo, optouse por estudar e simular o modelo sintético CO2STORE, do software ECLIPSE 2010.2, que implementa a injeção de $\mathrm{CO}_{2}$ em um aquífero salino.

\section{REFERÊNCIAS BIBLIOGRÁFICAS}

RAVAGNANI, A. T. F. S. G.; Modelagem Técnico-Econômico de Sequestro de $\mathrm{CO}_{2}$ Considerando Injeção em Campos Maduros. Ana Teresa Ferreira da Silva Gaspar Ravagnani. Tese de Doutorado. Universidade Estadual de Campinas, Faculdade de Engenharia Mecânica e Instituto de Geociências. Campinas - SP, 2007.

GAUSS CONSULTORES ASSOCIADOS LTDA. O Conceito de Sustentabilidade. Revista Banas Qualidade. Pág. 2. Outubro de 2008.

COSTA, I. V. L. da; Análise do Potencial Técnico do Sequestro Geológico de $\mathrm{CO}_{2}$ no Setor Petróleo no Brasil. Isabella Vaz Leal da Costa. Dissertação de Mestrado. Universidade Federal do Rio de Janeiro - UFRJ/COPPE. Rio de Janeiro, 2009.

STATOIL, 2011. Tecnologia de CCS (Carbon, Capture and Storage). Disponível em: <http://www.co2net.com>. Acesso em: 20 de outubro de 2013.

ROSA, A. J.; CARVALHO, R. S.; XAVIER, J. A. D; Engenharia de Reservatórios de Petróleo. Rio de Janeiro: Interciência, 2005.

SCHÜTZ, M. K, Estudo da Interação $\mathrm{CO}_{2}$-Rocha-Fluido no Processo de Carbonatação de Aquíferos Salinos. Marta Kerber Schütz. Dissertação de Mestrado. Pontifícia Universidade Católica do Rio Grande do Sul - PUCRS. Porto Alegre, 2010. 